\title{
Comparative study in treatment of haemangioma with oral propranolol and combination effect of oral propranolol and topical timolol solution
}

\author{
Ashok Laddha', Brijesh Kumar Lahoti ${ }^{1}$, Pavankumar More ${ }^{2 *}$, Shashi Shankar Sharma ${ }^{1}$, \\ Pooja Tiwari $^{2}$, Harshita Kakoriya ${ }^{2}$, Shashank Singh Baghel ${ }^{2}$, Ram Mohan Shukla ${ }^{2}$
}

\begin{abstract}
${ }^{1}$ Department of Paediatric Surgery, ${ }^{2}$ Department of Surgery, Mahatma Gandhi Memorial Medical College, Indore, Madhya Pradesh, India
\end{abstract}

Received: 01 March 2021

Revised: 19 March 2021

Accepted: 20 March 2021

\author{
*Correspondence: \\ Dr. Pavankumar More, \\ E-mail: morepa1pm@gmail.com
}

Copyright: $(\odot$ the author(s), publisher and licensee Medip Academy. This is an open-access article distributed under the terms of the Creative Commons Attribution Non-Commercial License, which permits unrestricted non-commercial use. distribution. and reproduction in anv medium. provided the original work is properlv cited.

\begin{abstract}
Background: Haemangioma of infancy usually regresses on its own but recently there has been trend of use of beta blockers like propranolol. Here we assess the improvement in efficacy of combination of propranolol with timolol in decreasing lesion size and colour change. And assess whether the combination decreases the duration of the treatment. Methods: Total of 40 patients were included in our study with surface haemangioma under 12 years. Divided in to two groups of 20 each oral propranolol and timolol and propranolol only, treated for 6 months and were assessed by monthly measurements of lesion dimensions using measuring tape, USG and colour changes noted by clinical photographs on monthly basis. VAS scale was used to grade the improvements. Comparisons were made between the groups with statistical analysis.

Results: VAS grade comparisons were insignificant $p>0.05$. Mean treatment duration was $4.65 \pm 2.601$ months for Propranolol with timolol group and 5.50 \pm 3.171 months for propranolol only group. Statistically significant outcomes between 2 groups were noted in the depth category and total volume reduction of the lesion with $\mathrm{p}=0.019$ and 0.033 respectively, in the subset of $0-12$ months only with $\mathrm{p}=0.038$.

Conclusions: Clinically there is Volumetric reduction in terms depth reduction and a decrease in duration of treatment. Propranolol $2-3 \mathrm{mg} / \mathrm{kg}$ and Timolol solution of $0.5 \%$ applied thrice over the lesion was well tolerated without any serious adverse events. The combination therapy fails to demonstrate a statistically approvable shorter period of treatment as well as better efficacy when compared to oral propranolol alone.
\end{abstract}

Keywords: Propranolol, Timolol, Haemangioma, Combined therapy, Efficacy

\section{INTRODUCTION}

Haemangioma are the benign vascular endothelial tumours. The majority of them are confined to skin; The distribution of surface haemangioma is mainly in the head and neck region. ${ }^{1}$ Haemangioma possess a characteristic clinical course marked by early growth and followed by spontaneous regression and disappearance. ${ }^{2}$ Haemangioma usually are medically less significant unless they undergo complications.
Haemangioma can be managed conservatively by opting for a passive approach of 'wait and watch policy' as they tend to resolve on their own, but lot of patients still need an intervention at the end of involution period if the tumour has not completely regressed. Although the waitand-watch approach to uncomplicated infantile haemangiomas exists, there has been a trending scope for active management to achieve early resolutions. But what justifies the interventions at an early age is the difficulty of prediction of duration of time for complete involution. 
The current evidences and studies state that the haemangioma is best treated in the proliferative phase. The majority of infantile haemangioma scarcely necessitated any medical or surgical interference in the older times. ${ }^{3}$ Medical line of treatment for clinically significant haemangiomas was restricted to a few drugs, which includes steroids-glucocorticoids, immunomodulators-interferon alfa, and rarely, chemotherapeutic drugs-vincristine and topical imiquimod. In the earlier days various types of medical surgical and minimal invasive techniques have been used to treat haemangioma. Since 2008 after Leaute-Lebrez et al proposal of beta-blockers, most specifically propranolol, has been preferred as first choice of treatment. ${ }^{4}$

Objectives were to study the effects of timolol solution as local application in conjugation with oral propranolol: A) to assess the improvement in efficacy of propranolol when treated in combination with timolol in terms of size reduction; $\mathrm{B}$ ) to assess whether addition of timolol to the oral propranolol lessens the duration of the treatment and thus whether it speeds up the haemangioma regression.

\section{METHODS}

From March 2019 to June 2020, 40 cases with surface infantile haemangioma were enrolled in the department of paediatric surgery, Mahatma Gandhi memorial medical college, Indore. The ages of the patients were decided to be 0 to 12 years. Diagnosis of infantile hemangioma was made based on patient history, clinical examination, ultrasound. Patients were randomly divided into two groups using a randomized number table. All patients' parents gave written informed consent to participate in the study. This prospective clinical study was approved by the MPMSU review board. The management protocol was designed for the clinical trial. Only those with surface haemangioma were included in the study. No patients with History of previous treatment for IHs (such as laser or steroid), age $>12$ years and heart disease, cardiac arrhythmia, asthma, broncho-obstructive disease, PHACE syndrome and prematurity were included. Patients were treated on Outpatient basis. The pre-treatment steps included procuring demographic data like name, age, sex, OPD number, address, contact number, history including presentation, location of lesion, age of onset, any previous treatment, any complications related to lesion like ulcerations, scarring etc. physical examination of lesion (note size, shape, consistency colour etc), electrocardiogram, paediatric cardiology opinion to start beta blocker therapy, blood glucose, baseline blood pressure, and clinical photographs. One group (20 patients with 7 males and 13 females) was treated using oral propranolol combined with topical timolol maleate, whereas the other group (20 patients with 5 males and 15 females) was treated with oral propranolol alone.
Oral propranolol (Ciplar $10 \mathrm{mg}$ tablet) given at a dose of 2 to $3 \mathrm{mg} / \mathrm{kg}$ divided in two doses per day. The $0.5 \%$ timolol maleate eye drops (Timolast eye drops $5 \mathrm{ml}$ ) were gently coated onto the haemangioma area in a thin layer using a medical swab. The ophthalmic solution was applied thrice daily.

Parents were trained on how to detect systemic and local side reactions and if necessary, to discontinue administration when any major side effects were observed like inability of the child to accept feeds, dullness in activity or perspirations. In such cases patient attenders were asked to stop medications and visit our emergency facility immediately. The first follow-up visit was performed after 2 weeks of therapy and scheduled monthly thereafter. At each clinic visit, the blood pressure, heart rate, and blood glucose were measured, as well as serial clinical photographs were obtained. Treatment was administered for a maximum period of 6 months or complete regression of lesions was harvested. Clinical responses to the treatment regimens based on the changes of size and colour of the haemangioma were assessed by measuring tape, ultrasound for depth and photographs at the onset of treatment, between treatment intervals, and at the conclusion of treatment.

The visual analogue scale was compared with the response to treatment. Two independent surgeons/clinicians blind to the patients assessed the efficacy by analysing the clinical photograph at baseline and the end of the treatment. The score used was visual analogue scale (VAS) with a range 0 to 100 . Here 0 represented at the start of treatment 100 represented complete response. Adverse effects of therapy were evaluated at each follow-up visit. Continuous variables, such as VAS score and treatment duration, were described as mean SD. Comparisons were made. $\mathrm{X}^{2}$ or Fisher exact test and the student test were used for categorical and quantitative variables. All analyses were performed with the SPSS software version 17 (SPSS Inc, Chicago, IL). A p value less than 0.05 was considered significant.

\section{Photograph analysis}

After receiving consent, photographic documentation of all lesions is performed on all patients presenting to our vascular anomalies centre. Haemangioma undergoing propranolol therapy were photographed in series before and during their treatment cycle. Interval examinations with photographs were performed to document treatment response. Formal review of the photographs was performed by 2 blinded observers who were physicians with variable levels of experience in the treatment of vascular anomalies. Disease response was graded for each patient from onset of therapy to final photo documentation. Hemangiomas were numerically rated VAS grading viz grade 4-Excellent (75-100) response, grade 3 -Better (51 to 75 ) response, grade 2 -Fair (26 to $50)$ response, grade 1 -Poor (0 to 25 ) response. 


\section{RESULTS}

Among the affected population of haemangioma female patients show the highest percentage 70 and $30 \%$ being male patients. In our study male and female ratio is variable, female is more affected than male patients. Out of 40 patients, the number of female patients is 28 and male patients are 12 . The male to female ratio is $1: 2.33$ (Table 1).

Table 1: Age and sex distribution of the patients of haemangioma under study.

\begin{tabular}{|lllll|}
\hline \multirow{2}{*}{ Age group (month) } & Sex & Female & Male & Total \\
\hline \multirow{2}{*}{$\mathbf{0 - 1 2}$} & Count & 21 & 10 & 31 \\
& $\%$ & 75.0 & 83.3 & 77.5 \\
\hline \multirow{2}{*}{$\mathbf{1 3 - 3 6}$} & Count & 6 & 1 & 7 \\
\cline { 2 - 5 } & $\%$ & 21.4 & 8.3 & 17.5 \\
\hline \multirow{2}{*}{$\mathbf{3 7}$} & Count & 1 & 1 & 2 \\
\hline \multirow{2}{*}{ Total } & $\%$ & 3.6 & 8.3 & 5.0 \\
\hline & Count & 28 & 12 & 40 \\
\hline
\end{tabular}

In our study most of the lesion were located at head, nose and face region, out of 40 patient 23 lesions were located in head face, nose and 9 lesions were located at limb, 4 lesions located at perineal region and 4 lesions located in trunk, so the most common site of the infantile hemangioma head, face and nose region (Table 2).

Table 2: Distribution of study populations according to the location of lesion.

\begin{tabular}{|l|l|}
\hline Location & No. of patients \\
\hline Face & 9 \\
\hline Nose & 1 \\
\hline Head and scalp & 13 \\
\hline Limb & 9 \\
\hline Trunk & 4 \\
\hline Perineal & 4 \\
\hline Total & 40 \\
\hline
\end{tabular}

From the data collected the mean age of onset of haemangioma of two groups, the difference between the mean values of two groups is $4.025 \pm 2.678$ and $4.025 \pm 2.43$ respectively for group propranolol and timolol $(\mathrm{P}+\mathrm{T})$ and propranolol only $(\mathrm{P})$, was found to be statistically non-significant $(\mathrm{p}>0.05)$.

The mean age of two groups presenting to OPD. The difference between the mean values of two groups was found to be statistically non-significant $(\mathrm{p}>0.05)$. Mean of group 1- $(9.8 \pm 13.117)$ months and group $2(8.8 \pm 8.806)$ months.

The pre-treatment and Post treatment measurements of lesions have been compared between the two groups. Group 1=Propranolol and timolol and group 2=
Propranolol only. Significant difference in change of measurement after treatment is noted in depth with mean of $0.8 \pm 0.410 \mathrm{~cm}$ for group $1(\mathrm{P}+\mathrm{T})$ and mean of $1.150 \pm 0.489 \mathrm{~cm}$ for group $2(\mathrm{P})$ with $\mathrm{p}=0.019$ and parameter that showed significant change with $\mathrm{p}$ value, $\mathrm{p}=0.033$ was the $\%$ of volume reduced being $67.287 \%$ and $55.547 \%$ reduction respectively for group 1 and group 2 (Table 3 ).

In another subset of patients with age group 0-12 months were compared after completion of 6 months of treatment and only the depth parameter was found to have statistically significant change was the depth $0.765 \pm 0.437$ $\mathrm{cm}$ and $1.143 \pm 0.535 \mathrm{~cm}$ for group 1 and group 2 respectively $\mathrm{p}=0.038$ (Figure 1 ).

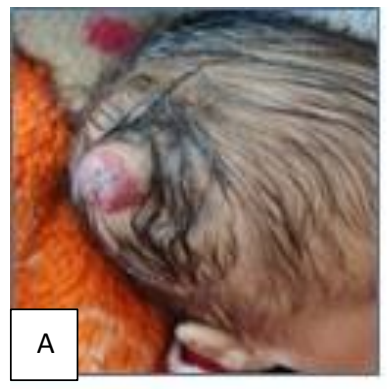

Dav 1

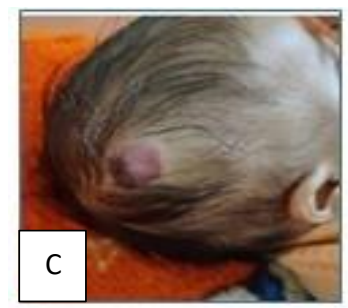

1 month

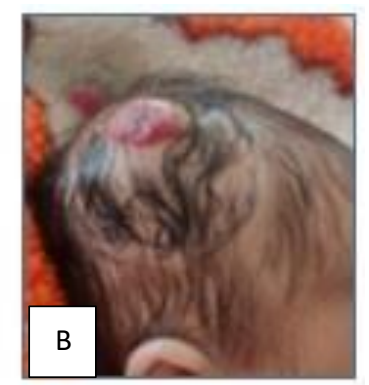

Day 15

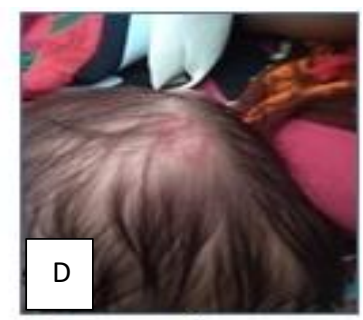

2 months

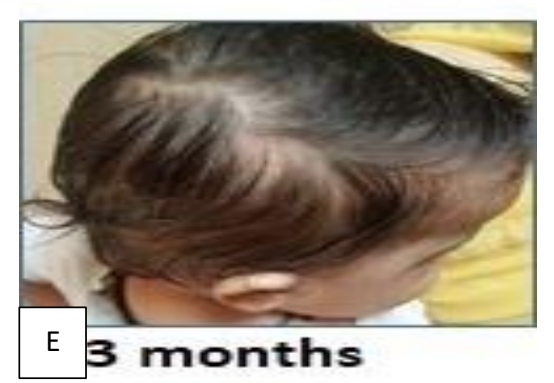

Figure 1: Serial photographs of a patient treated with combination of oral propranolol and topical timolol showing complete resolution (age group 0-12 months).

The comparison of mean of VAS Grades of two Groups was made at the end of 6 months the mean VAS grading of group 1 was found to be $2.850 \pm 0.587$ vs $2.700 \pm 0.470$ for group 2. With $\mathrm{T}$ test value $=0.892$ and $\mathrm{p}=0.378$. the results were insignificant. So were the results at 1 month and 3-month comparisons. The mean analogue score of groups 1 (propranolol and timolol) is always higher than the group 2 (propranolol) (Table 4). 
Table 3: Comparison of different variables (pre-treatment length, breadth and depth and post treatment length, breadth and depth) of two groups.

\begin{tabular}{|c|c|c|c|c|c|c|c|}
\hline Variable & Group & $\mathbf{N}$ & Mean $(\mathrm{cm})$ & Std. deviation & T test & $P$ value & Result \\
\hline \multirow{2}{*}{ Pre-length } & 1 & 20 & 3.100 & 1.210 & \multirow{2}{*}{0.120} & \multirow{2}{*}{0.905} & \multirow{2}{*}{ Non-SIG } \\
\hline & 2 & 20 & 3.150 & 1.424 & & & \\
\hline \multirow{2}{*}{ Pre-breadth } & 1 & 20 & 1.700 & 0.657 & \multirow{2}{*}{0.000} & \multirow{2}{*}{1.000} & \multirow{2}{*}{ Non-SIG } \\
\hline & 2 & 20 & 1.700 & 0.733 & & & \\
\hline \multirow{2}{*}{ Pre depth } & 1 & 20 & 1.450 & 0.510 & \multirow{2}{*}{0.632} & \multirow{2}{*}{0.531} & \multirow{2}{*}{ Non-SIG } \\
\hline & 2 & 20 & 1.350 & 0.489 & & & \\
\hline \multirow{2}{*}{ Pre-volume $\left(\mathrm{cm}^{3}\right)$} & 1 & 20 & 7.200 & 4.137 & \multirow{2}{*}{-0.242} & \multirow{2}{*}{0.810} & \multirow{2}{*}{ Non-SIG } \\
\hline & 2 & 20 & 7.700 & 8.253 & & & \\
\hline \multirow{2}{*}{ Post-length } & 1 & 20 & 1.800 & 1.005 & \multirow{2}{*}{0.145} & \multirow{2}{*}{0.885} & \multirow{2}{*}{ Non-SIG } \\
\hline & 2 & 20 & 1.750 & 1.164 & & & \\
\hline \multirow{2}{*}{ Post breadth } & 1 & 20 & 1.300 & 0.657 & \multirow{2}{*}{0.636} & \multirow{2}{*}{0.529} & \multirow{2}{*}{ Non-SIG } \\
\hline & 2 & 20 & 1.450 & 0.826 & & & \\
\hline \multirow{2}{*}{ Post depth } & 1 & 20 & 0.800 & 0.410 & \multirow{2}{*}{-2.451} & \multirow{2}{*}{0.019} & \multirow{2}{*}{ Significant } \\
\hline & 2 & 20 & 1.150 & 0.489 & & & \\
\hline \multirow{2}{*}{ Post volume $\left(\mathrm{cm}^{3}\right)$} & 1 & 20 & 2.700 & 3.011 & \multirow{2}{*}{-0.877} & \multirow{2}{*}{0.386} & \multirow{2}{*}{ Non-SIG } \\
\hline & 2 & 20 & 3.90 & 5.330 & & & \\
\hline \multirow{2}{*}{$\%$ vol reduced } & 1 & 20 & 67.287 & 17.110 & \multirow{2}{*}{2.216} & \multirow{2}{*}{0.033} & \multirow{2}{*}{ Significant } \\
\hline & 2 & 20 & 55.547 & 16.393 & & & \\
\hline
\end{tabular}

Pre $=$ Pre-treatment, Post $=$ Post treatment, Group 1=Propranolol and Timolol, Group 2=Propranolol.

Table 4: Comparison of visual analogue score grades of two groups.

\begin{tabular}{|llllll|}
\hline Variable & Group & N & Mean VAS grade & Std. Deviation & Result \\
VAS_1 month & 1 & 20 & 1.800 & 0.768 & Non-SIG \\
\cline { 2 - 6 } VAS_3 month & 2 & 20 & 1.650 & 0.745 & Non-SIG \\
& 1 & 20 & 2.450 & 0.759 & \\
\multirow{3}{*}{ VAS_6 month } & 2 & 20 & 2.150 & 0.813 & Non-SIG \\
& 1 & 20 & 2.850 & 0.587 & \\
& 2 & 20 & 2.700 & 0.470 & 3.171 \\
\end{tabular}

VAS-Visual analogue scale.

The mean duration of treatment, the difference between the mean values of two groups was found to be statistically non-significant $(\mathrm{p}>0.05)$. mean of group 1 is (4.65 \pm 2.601$)$ and group 2 is $(5.50 \pm 3.171)$ months.

The mean \pm SD of heart rate and Random blood sugar levels of 2 groups evaluated at every month, compared and analysed during and at the end of the treatment. There was no significant difference in the both parameters. The mean values in both groups were almost similar at every months' reading.

\section{DISCUSSION}

Propranolol and other beta blockers are the front runners in the treatment of infantile haemangioma (IH). ${ }^{5}$ Propranolol is now the more effective and safe therapy in comparison to the rest of the previously established modes of treatment, especially when those treatments have failed. ${ }^{6}$ Studies done since the Leaute-Labreze et al proposal have suggested it as first-line therapy. ${ }^{4}$ Inaccessibility for surgery, lesions with deep component, severe ulceration, cosmetic disfigurement are some of the other indications however parental concern and apprehension is the most important indication of all to start early therapy.

Owing to the adverse effects, it is important to try and lessen the duration of propranolol therapy, hence in our study topical timolol solution was combined with oral propranolol to look for improvement in outcome rates and to determine whether addition of timolol decreases the duration of treatment. ${ }^{7}$ A very few studies have been carried out on combination therapies (systemic and local) with considerable positive outcome.

In our institutional study we found out that the incidence in Indore region is $2 \%$. There were 63 patients in two 
years of period of study out of 3233 patients visiting paediatric surgery OPD. The overall incidence in general is about $10 \%$ in general population. This decreased number patient could be due to distribution of patients to various health care centres in this region of central India and the impact of COVID-19 pandemic and its lockdown status.

We found no significant differences in the Sex ratio, age of onset, age of presentation and pre-treatment sizes of lesions as well as the age of onset of the lesions between two comparative groups ( $p>0.05)$., matching most of the parameters before initiating the therapy for both groups. Thus, accuracy of results could be established by the elimination of bias to a minimum.

The anatomical distribution of the hemangioma lesions was maintained in our study as well. In our study of 40 patients most of lesion were located in head, face and nose region which cosmetically are very important site. Out of 40 patients $57.5 \%$ lesions were located in head face, nose and $22.5 \%$ lesion located in limbs, $10 \%$ lesions located in pernieal region and $10 \%$ lesions located in trunk, so site of the infantile hemangioma most common in head face and nose region. These findings were consistent with findings of Finn et al with distribution of $60 \%$ in head and neck, $25 \%$ over the trunk and $15 \%$ on extremities. ${ }^{1}$ Similar anatomical distribution was also seen in the literature as in the studies of Katona et al and Qin et al. ${ }^{8,9}$

In our series the mean duration of the treatment was (4.65 \pm 2.6$)$ months for Propranolol + timolol group and $(5.5 \pm 3.17)$ months for only propranolol group which was found to be non-significant rendering no shortening of duration of therapy or speeding up of action of propranolol upon addition of timolol to the systemic therapy $(p>0.05$ or $p=0.360)$. Similarly mean duration of treatment of 4.5 months for propranolol and timolol and 5.3 months for propranolol only was seen in the study done by Gong et al. ${ }^{7}$

Also, the mean VAS grades of the two groups at the end of study period was found to be insignificant with mean VAS grade of $\mathrm{P}+\mathrm{T}$ group being $(2.85 \pm 0.587)$ and for Propranolol mean VAS grade was $(2.7 \pm 0.470)$ inferring that statistically there was no great difference of improvement in the combined therapy $(\mathrm{p}>0.05$ or $\mathrm{p}=0.378)$.

In terms of the volume reduction of the lesion at the end of study the combination therapy $(\mathrm{P}+\mathrm{T})$ was found to be more efficacious than the monotherapy (only propranolol), volume reduction percentage was $(67.28 \pm 17.11)$ percentage for combined therapy group $(\mathrm{P}+\mathrm{T})$ and $(55.547 \pm 16.39)$ percentage for the single therapy group i.e., only propranolol, with $\mathrm{p}=0.033$.

When the analysis was further carried on for the earlier age group, reduction in terms of depth was found to be better in the propranolol and timolol group (depth $0.765 \pm 0.437 \mathrm{~cm}$ ) than the propranolol (depth $1.143 \pm 0.535 \mathrm{~cm})$ at the end of 6 months $(\mathrm{p}=0.038)$. In the parallel studies quite contrary to our findings- Li et al found in their study series that there was significant reduction of colour fading in the experimental group $(\mathrm{P}+\mathrm{T})$ (mean VAS score of $8.6 \pm 1.39)$ than that in the control group $(7.18 \pm 1.71)$ with $(\mathrm{p}=0.043) .{ }^{10}$ whereas the reduction of sizes in the experimental group $(\mathrm{P}+\mathrm{T})$ $(8.00 \pm 1.75)$ had no significant difference than that in the control group $(7.59 \pm 1.80)$ with $(\mathrm{p}=0.51)$. A randomized control trial (RCT) conducted by Qiao et al from 5 different studies Chen et al, Gong et al, Li et al, Du et al, Marey et al. ${ }^{10-12}$ It was derived that that combined treatment was associated with a higher response rate compared to oral propranolol alone $(\mathrm{RR}=1.14,95 \% \mathrm{CI}$ : 1.02 to $1.29 ; \mathrm{p}=0.03 ;$ ) with no significant heterogeneity ( $\mathrm{p}$ for Cochrane's $\mathrm{Q}$ test $=0.37, \mathrm{I} 2=6 \%$ ). Moreover, the incidence of adverse events was comparable between the two groups $(\mathrm{RR}=0.80, \mathrm{p}=0.24)$.

Compared with propranolol alone, the combination therapy failed to show better results in terms of shortening of duration of treatment and ameliorating the efficacy of propranolol. However, it was found that volumetric reduction was better in combination therapy than propranolol alone. Effects were seen better when the treatment was started in early age groups that is 0-6 months.

Known adverse effects of beta blockers mentioned in the literature are bradycardia, hypoglycemia, hypotension, pulmonary complications and GI disturbances. Side effects like hypoglycemia, bradycardia remained the similar even after addition of timolol to propranolol.

In our study there is no significant change of heart rate (pulse rate) after treatment of oral propranolol and indicate propranolol can be used safely in children as outpatient basis along with timolol. In our study bradycardia was watched for and noted that after initial treatment administration there was a mean difference of 3 beats per minute during first fortnight. Later mean change was 2-7 beats per month, but none of the patients HR was reduced more than $97 \mathrm{bpm}$.

No adverse events like hypotension were noted. Although 3 (1 from $\mathrm{P}+\mathrm{T}$ group; 2 patients from propranolol group) of the patients had mild dizziness and inability to feed at the start of treatment who were asked to stop and restarted once the symptoms subsided. 4 patients (2 belonging to each group) had diarrhoea which subsided with symptomatic care. Since diarrhoea is a very common ailment in our country the events could not be directly associated with the therapy given.

With regard to the side effects of the combined therapy compared to propranolol alone our findings were consistent with these following studies. In the study by Gong et al. ${ }^{12}$ One child in the group given both drugs 
developed loss of appetite and vomiting. In the propranolol alone group one patient had severe diarrhoea, and two had different degrees of lethargy and loss of appetite. In the study by $\mathrm{Li}$ no et al major side effects from the medication were reported. ${ }^{10} 2$ patients in the experimental $(\mathrm{P}+\mathrm{T})$ group experienced diarrhoea, while 3 patients in the control group suffered from diarrhoea. Adverse events like bradycardia, hypotensive episode, or hypoglycemia, were not experienced.

Timolol is a nonselective $\beta$ adrenergic antagonist and is found to be 8 times more potent than propranolol hence its systemic absorption could lead to devastating side effects. In our study no major side effects were reported by parents in the combination group.

In our experience we found that most of the patients who belonged to the younger age group had faster response to the combination therapy, in terms of size reduction, colour changes and return of skin to normal tone. Maximum of 8 months of treatment seemed convincingly good for children younger than 12 months, preferably younger than 6 months, because then the treatment would be carried out in proliferative phase of the lesion.

Although our results did not statistically justify that combination therapy would shorten the duration and improve the efficacy of propranolol, but clinically there was satisfactory reduction in size and volume as well as the colour of the haemangioma lesions. It is noteworthy that the younger children group $1(\mathrm{P}+\mathrm{T})$ responded well and faster to the treatment and thus a study with larger sample size can demonstrate the better efficacy of the combination therapy over the propranolol therapy in the treatment of haemangiomas.

\section{Limitations}

Study needs to be carried out in a larger cohort which will give us an exact figure of significant outcomes. Covid pandemic in 2020 led to the drastic fall in the number patients following up the clinics and had a lapse in treatment due to inaccessibility to medications. VAS scoring could have been further made specific if scores like-10 to +10 were used instead of percentage-based grade scoring for colour change.

\section{CONCLUSION}

In our study we found out that the propranolol 2-3mg per $\mathrm{kg}$ and timolol solution of $0.5 \%$ applied thrice over the lesion was well tolerated by all the patients without any serious adverse events. The Propranolol and Timolol combination therapy fail to demonstrate a statistically approvable shorter period of treatment as well as the efficacy when compared to oral propranolol alone. But clinically there is Volumetric reduction in terms depth reduction and a decrease in duration of treatment. This was found to be better in combination group than propranolol alone and was significant for early age group patients. i.e., 0-12 months. The regression of size and colour clearance observed clinically is sufficiently convincing to carry out this study on a larger sample size in future.

Propranolol and timolol could be a potential first line choice in future, for which large sample sized studies are required.

\section{ACKNOWLEDGEMENTS}

Author would like to thank to Dr. Sachin Verma and Dr. Santosh More for their contribution as visual analogue score analysers.

\section{Funding: No funding sources}

Conflict of interest: None declared

Ethical approval: The study was approved by the Institutional Ethics Committee

\section{REFERENCES}

1. Finn MC, Glowacki J, Mulliken JB. Congenital vascular lesions: clinical application of a new classification. J Pediatr Surg. 1983;18(6):894-900.

2. Luu M, Frieden IJ. Haemangioma: clinical course, complications and management. $\mathrm{Br} \mathrm{J}$ Dermatol. 2013;169(1):20-30.

3. Margileth AM, Museles M. Cutaneous hemangiomas in children. Diagnosis and conservative management. JAMA. 1965;194(5):523-6.

4. Léauté-Labrèze C, Dumas de la Roque E, Hubiche T, Boralevi F, Thambo JB, Taïeb A. Propranolol for severe hemangiomas of infancy. $\mathrm{N}$ Engl J Med. 2008;358(24):2649-51.

5. Nguyen HP, Pickrell BB, Wright TS. Beta-blockers as therapy for infantile hemangiomas. Seminar's plastic surg. 2014;28(2):87-90.

6. Gunturi N, Ramgopal S, Balagopal S, Scott JX. Propranolol therapy for infantile hemangioma. Indian Pediatr. 2013;50(3):307-13.

7. Li X, Yang K, Li H, Huo R. Propranolol Treatment for Infantile Hemangiomas: Short-Term Adverse Effects and Follow-Up to Age Two. BioMed Research Int. 2019;2728952:9.

8. Katona G, Csa'ka'nyi Z, Ga'cs E. Propranolol for infantile haemangioma: striking effect in the first weeks. Int J Pediatr Otorhinolaryngol 2012;76:174650.

9. Qin ZP, Liu XJ, Li KL. Treatment of infantile hemangiomas with low-dose propranolol: evaluation of short-term efficacy and safety. Zhonghua Yi Xue Za Zhi. 2009;89:3130-4.

10. Li G, Xu DP, Tong S, Xue L, Sun NN, Wang XK. Oral Propranolol with Topical Timolol Maleate Therapy for Mixed Infantile Hemangiomas in Oral and Maxillofacial Regions. J Craniofac Surg. 2016;27(1):56-60.

11. Qiao J, Lin J, Zhang D, Li J, Chen C, Yu H et al. Efficacy of Combined Topical Timolol and Oral 
Propranolol for Treating Infantile Hemangioma: A Meta-Analysis of Randomized Controlled Trials. Front Pharmacol. 2020;11:554847.

12. Gong H, Xu DP, Li YX, Cheng C, Li G, Wang XK. Evaluation of the efficacy and safety of propranolol, timolol maleate, and the combination of the two, in the treatment of superficial infantile haemangiomas. Br J Oral Maxillofac Surg. 2015;53(9):836-40.
Cite this article as: Laddha $\mathrm{A}$, Lahoti BK, More $\mathrm{P}$, Sharma SS, Tiwari P, Kakoriya H, Baghel SS, Shukla RM. Comparative study in treatment of haemangioma with oral propranolol and combination effect of oral propranolol and topical timolol solution. Int Surg J 2021;8:1148-54 